BMJ Open Sport \& Exercise Medicine

\title{
Mental health difficulties among professional jockeys: a narrative review
}

\author{
Lewis King (1) , ${ }^{1}$ Sarah Jane Cullen, ${ }^{1}$ Adrian McGoldrick, ${ }^{2}$ Jennifer Pugh, ${ }^{2}$ \\ Giles Warrington, ${ }^{3,4}$ Gary Woods, ${ }^{5}$ Ciara Losty ${ }^{1}$
}

To cite: King L, Cullen SJ, McGoldrick A, et al. Mental health difficulties among professional jockeys: a narrative review. BMJ Open Sport \& Exercise Medicine 2021;7:e001078. doi:10.1136/ bmjsem-2021-001078

Accepted 8 April 2021
Check for updates

Cㄱ Author(s) (or their employer(s)) 2021. Re-use permitted under CC BY-NC. No commercial re-use. See rights and permissions. Published by BMJ.

${ }^{1}$ Sport and Exercise Sciences, Waterford Institute of Technology, Waterford, Ireland ${ }^{2}$ Irish Horseracing Regulatory Board, Kildare, Ireland ${ }^{3}$ Health Research Institute, University of Limerick, Limerick, Ireland

${ }^{4}$ Physical Education and Sport Sciences, University of Limerick Limerick, Ireland

${ }^{5}$ School of Medicine, Dentistry and Biomedical Sciences, Queen's University Belfast, Belfast, UK

Correspondence to Lewis King;

lewis.king@postgrad.wit.ie

\section{ABSTRACT}

Introduction Emerging academic literature and highprofile disclosures of mental health difficulties and mental illness from current and former professional jockeys suggest that further exploration of the mental health of jockeys is required. To date, a comprehensive review of jockeys' mental health has yet to be conducted. Objectives To examine the existing literature related to jockeys' mental health, including the prevalence of symptoms associated with mental health difficulties and help-seeking.

Design A narrative review of the literature was conducted with articles screened from inception until January 2021.

Results Sixteen studies were included in the narrative review. Studies covered a range of mental health difficulties which included mood (depression), anxiety, distress, disordered eating and substance misuse. Rates of help-seeking among jockeys were also explored. Results indicated that jockeys reported higher levels of depressive and anxiety symptoms compared with other elite athletes. Substance misuse, in particular adverse alcohol use, also appears greater among jockeys than other elite athletes. Distress symptoms appear comparable with other elite athletes. Risk factors for mental health difficulties included injury, perceived stress, athlete burnout, career dissatisfaction and the contemplation of retirement. Weight-making negatively impacts jockeys' mood and attitudes towards eating, with lower competitive riding weights associated with more disordered eating attitudes. Moreover, help-seeking from mental health professionals appears low.

Conclusion The review identifies a high prevalence of symptoms of mental health difficulties among professional jockeys. Applied recommendations and future research considerations are proposed throughout the review article.

\section{INTRODUCTION}

Horse racing is a high-risk sport that places exacting physical $^{1-5}$ and psychological ${ }^{6-11}$ demands on jockeys. There is increasing evidence to indicate that jockeys experience significant levels of mental health difficulties (MHDs), possibly as a result of their distinctive lifestyles and the stresses particular to their profession. ${ }^{6} 8$ King et al identified four core categories of stressors experienced by jockeys, related to: competition (eg, performance

\section{What is already known?}

- Jockeys experience a multitude of stressors throughout their careers that may impact their mental health.

- Studies have explored the physical and psychological interplay of weight-making on jockeys' mental health, although an updated review has yet to be conducted exploring the wider mental health literature.

- Early studies indicate that depressive symptoms may be greater among jockeys than other elite athletes.

\section{What are the new findings?}

- The present review provides an overview of updated and contemporary research exploring the mental health of professional jockeys.

- Prevalence of depression and anxiety symptoms and adverse alcohol use appear greater among professional jockeys than athletes from other sports.

- Risk factors for anxiety and distress symptoms among jockeys include athlete burnout, career dissatisfaction and the contemplation of retirement. Further research is needed to identify other general and sport-specific risk factors.

- Help-seeking among the jockey population appears low.

slumps, pressure, injury and opponents); the wider racing industry (eg, making weight, workload and travel demands); interpersonal challenges (eg, relationships with trainers, other jockeys and expectations of others); and career stressors (eg, career uncertainty, career opportunities and transitions). A recent study examined jockeys' mental health using validated screening questionnaires and highlighted that almost $80 \%$ of jockeys in Ireland met the threshold for at least one of the MHDs assessed (depression, generalised anxiety, psychological distress and adverse alcohol use ${ }^{6}$ ). Moreover, $87 \%$ of 105 jockeys who participated in an industry-wide survey in the UK reported experiencing 'stress, anxiety or depression' during the previous 12 months, 
with the profession's loneliness, financial uncertainty and relentless workload highlighted as key stressors. ${ }^{12}$ While a previous review article specifically explored the physical and psychological implications of jockeys' weight-making strategies, ${ }^{4}$ there has not yet been an attempt to review and consolidate the findings of the expanding wider mental health literature. The current review therefore aims to examine professional jockeys' mental health beyond the deleterious effects of making weight, with a focus on the following: mood, anxiety, distress, disordered eating, substance misuse and help-seeking.

\section{Methodological aspects}

A computer-based literature search was undertaken independently by two of the authors (LK and GW), comprising of PubMed and Google Scholar databases, as well as grey literature (eg, industry-funded reports) from inception to January 2021. Keywords searched included 'jockey' OR 'horse racing' AND 'common mental disorder' OR 'mental health' OR 'mental health difficulties' OR 'depression' OR 'mood' OR 'anxiety' OR 'eating disorder' OR 'substance misuse' OR 'help seeking' OR 'psychology' OR 'psychiatry'. A manual search of reference lists was also conducted.

\section{Study inclusion and exclusion criteria}

LK and GW independently screened articles and abstracts for eligibility. Studies were required to have met the following inclusion criteria:

1. Professional jockeys.

2. Quantitative or qualitative data on symptoms of MHDs or help-seeking.

3. Written in English.

Studies were excluded from the review article if they met the following criteria:

1. Non-professional jockey status (eg, amateur jockeys).

2. Review articles.
3. Book chapters.

4. Conference abstracts.

5. Full text of the article was not available.

\section{Review terminology}

An outline of the explanations of the terms used throughout the review article is included in table 1.

\section{RESULTS}

In total, 16 studies were included in the review. The studies were published between 1987 and 2020 and included jockeys from the UK $(n=8)$, Ireland $(n=4)$, South Africa $(n=1)$, New Zealand $(n=1)$, Australia $(n=1)$ and the USA $(n=1)$. A variety of study designs were employed to collect data, including cross-sectional $(\mathrm{n}=9)$, experimental $(\mathrm{n}=2)$, semistructured interviews and focus groups $(n=2)$, mixed-methods $(n=2)$ and a case study $(n=1)$. Studies used either male $(n=7)$ or mixedgender $(n=8)$ participants. One study did not state the gender of participants. Studies explored mood, ${ }^{68101314}$ anxiety, ${ }^{68}$ distress, ${ }^{6814}$ disordered eating, ${ }^{1014-19}$ substance misuse ${ }^{611}$ and help-seeking. ${ }^{612}$ Full details of the studies are reported in table 2 .

\section{Mood}

Two studies have comprehensively examined professional jockeys for the prevalence of depressive symptoms. Losty et al explored depressive symptoms using the Center for Epidemiologic Studies Depression Scale (CES-D) and found that $57 \%$ of professional jockeys met the questionnaire's caseness for depression based on a cut-off score of 16 or greater. No difference was observed between professional flat and national hunt jockeys. Building on the previous study by Losty $e t a l,{ }^{8}$ King $e t a l,{ }^{6}$ using the CES-D and same cut-off score, found that 29 of 84 jockeys $(35 \%)$ met the threshold indicative of a depressive disorder. However, in contrast to the work of Losty

Table 1 Review terminology

\section{Term Definition}

Mental health Mental health has been defined as a 'state of well-being in which every individual realises his or her own potential, can cope with the normal stresses of life, can work productively and fruitfully, and is able to make a contribution to her or his community, ${ }^{67}$

Mental health Throughout this review article, we refer to MHDs, often labelled as common mental disorders, which difficulties encompass depression, generalised anxiety disorder, panic disorder, phobias, social anxiety disorders, (MHDs) obsessive-compulsive disorder and post-traumatic stress disorder. ${ }^{68}$

Prevalence The present review article explores prevalence of MHDs among professional jockeys. Many of the studies discussed feature self-report data, thus, the term prevalence relates to a prevalence of symptoms, rather than prevalence of a diagnosed mental health disorder obtained via a clinical interview with a mental health professional. The percentages elicited throughout the review article refer to the number of jockeys who met the threshold indicative of MHDs based on a validated cut-off score for each self-report questionnaire.

Flat jockeys Flat jockeys compete in often short races $(1-4 \mathrm{~km})$ with no obstacles. Minimum competitive riding weights for flat jockeys vary between each racing jurisdiction. In Ireland, minimum and maximum riding weights are set at $8 s t 4 \mathrm{lbs}(52.6 \mathrm{~kg} / 116 \mathrm{lbs})$ and $9 \mathrm{st} 12 \mathrm{lbs}(62.6 \mathrm{~kg} / 138 \mathrm{lbs})$, respectively.

National hunt National hunt jockeys, often referred to as jump jockeys, compete in longer races (3.2-7.2 km) with obstacles jockeys known as hurdles or fences. Minimum and maximum riding weights for national hunt jockeys are set at 9st 10 lbs $(61.7 \mathrm{~kg} / 136 \mathrm{lbs})$ and $11 \mathrm{st} 12 \mathrm{lbs}(75.3 \mathrm{~kg} / 166 \mathrm{lbs})$, respectively. 
空

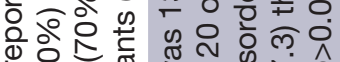

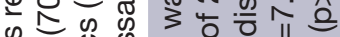
क ज क की क्ष $\stackrel{0}{=}$ 흥 बे

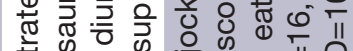
के

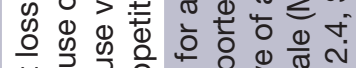

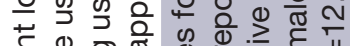

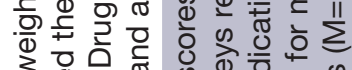
उ

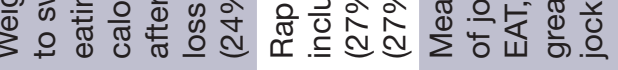

$\frac{\overline{0}}{\frac{0}{\sigma}}$

항

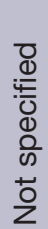

꾸 줌

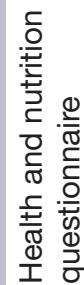

苋.

离

음

葛

为

क्ष

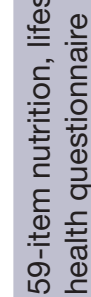

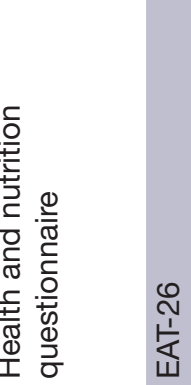

ญ̊ํํ

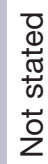

O̊.

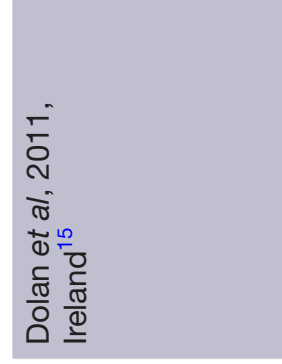

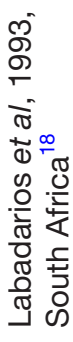

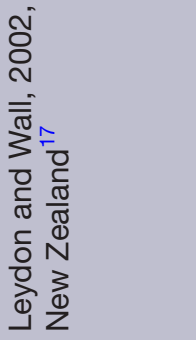




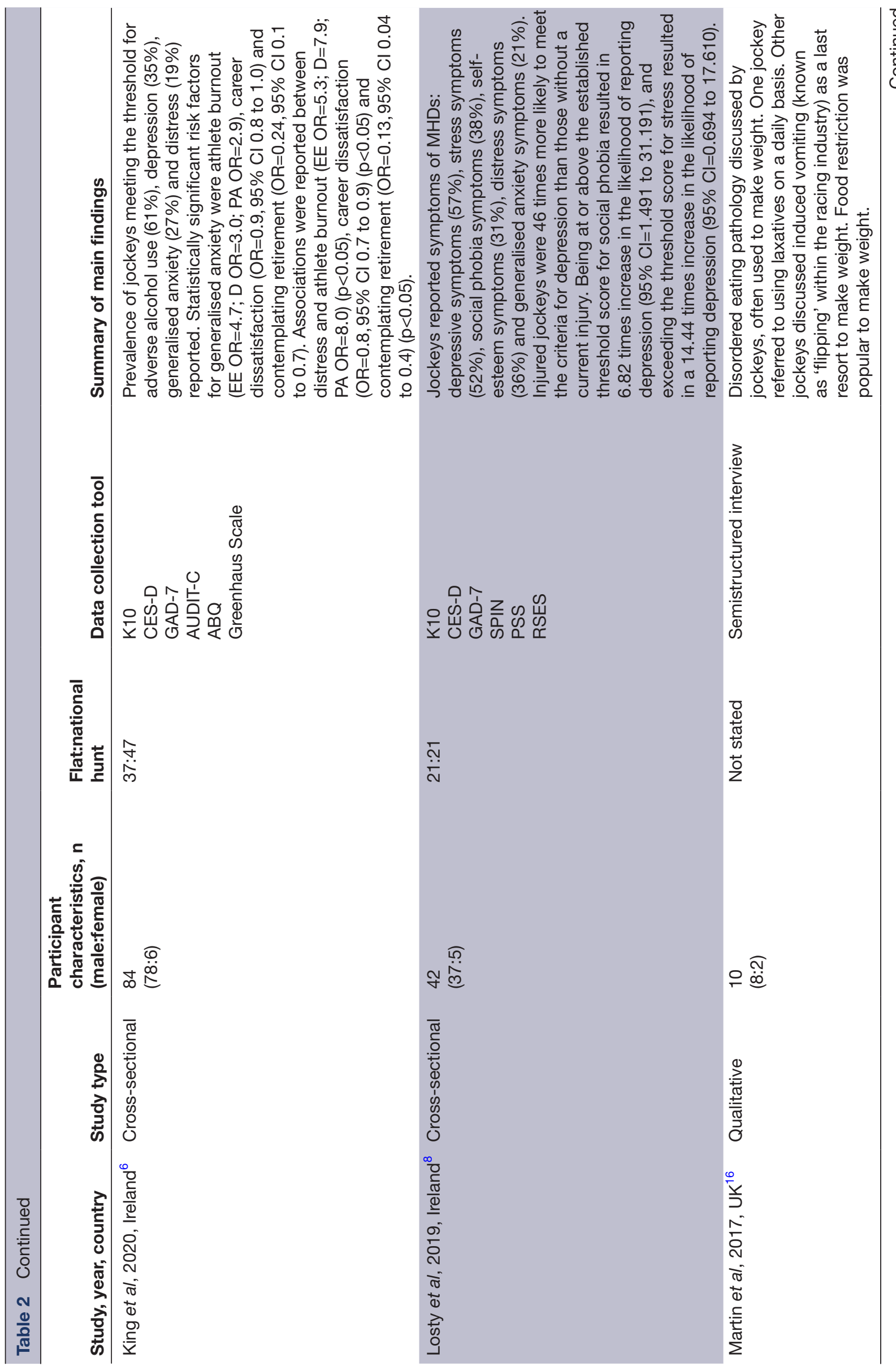

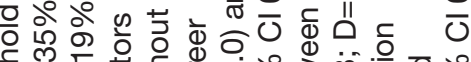
क 은 (1) क

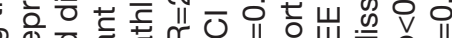

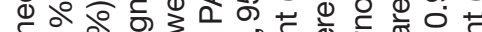

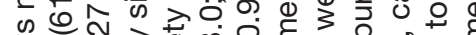

बi $\begin{gathered}0 \\ \overline{0}\end{gathered}$

으 $\overline{0}$ 击

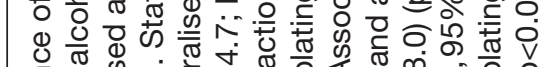

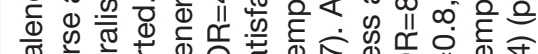

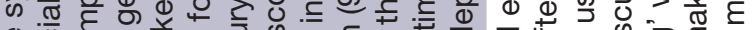

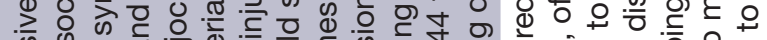

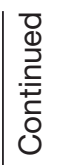




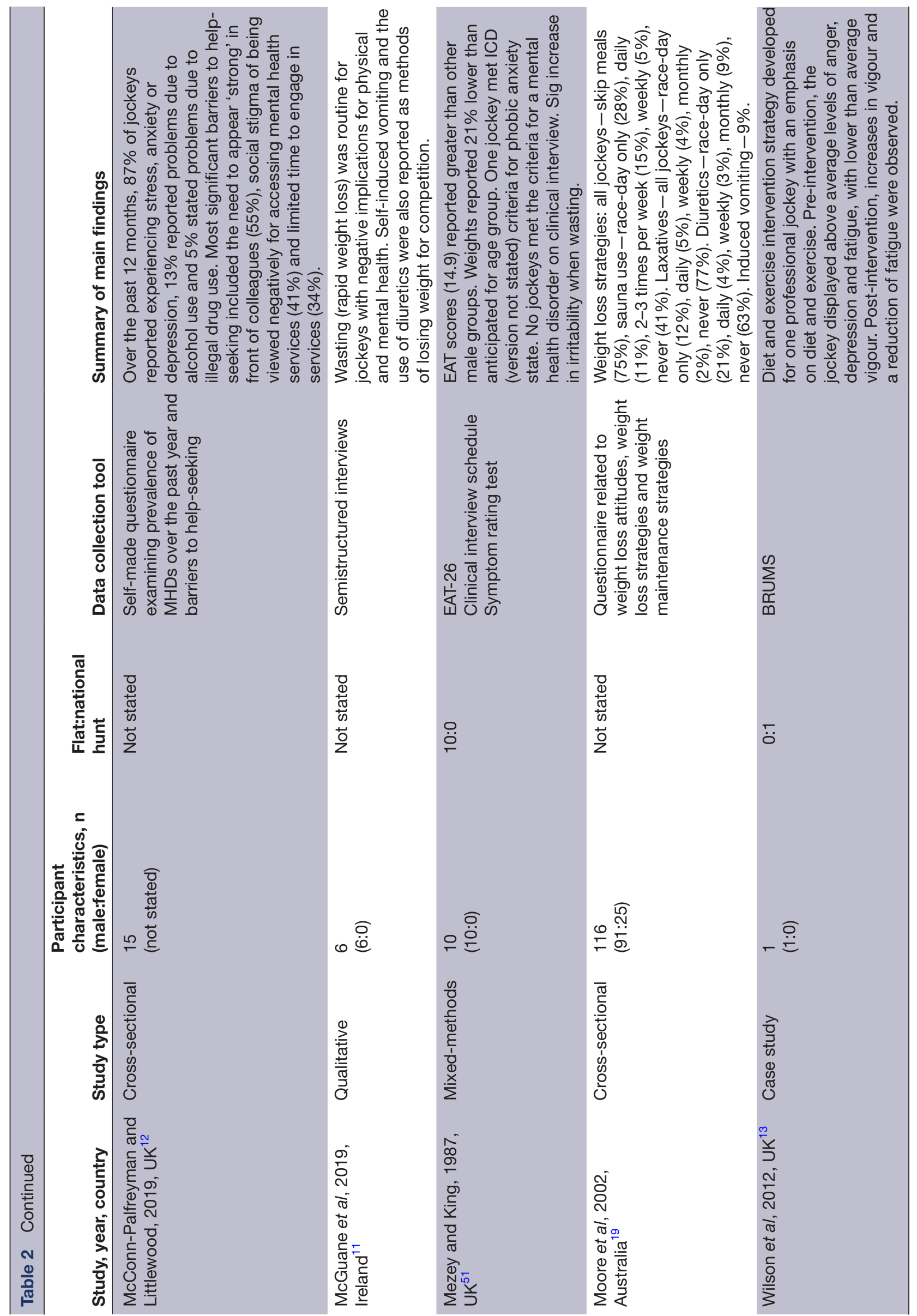




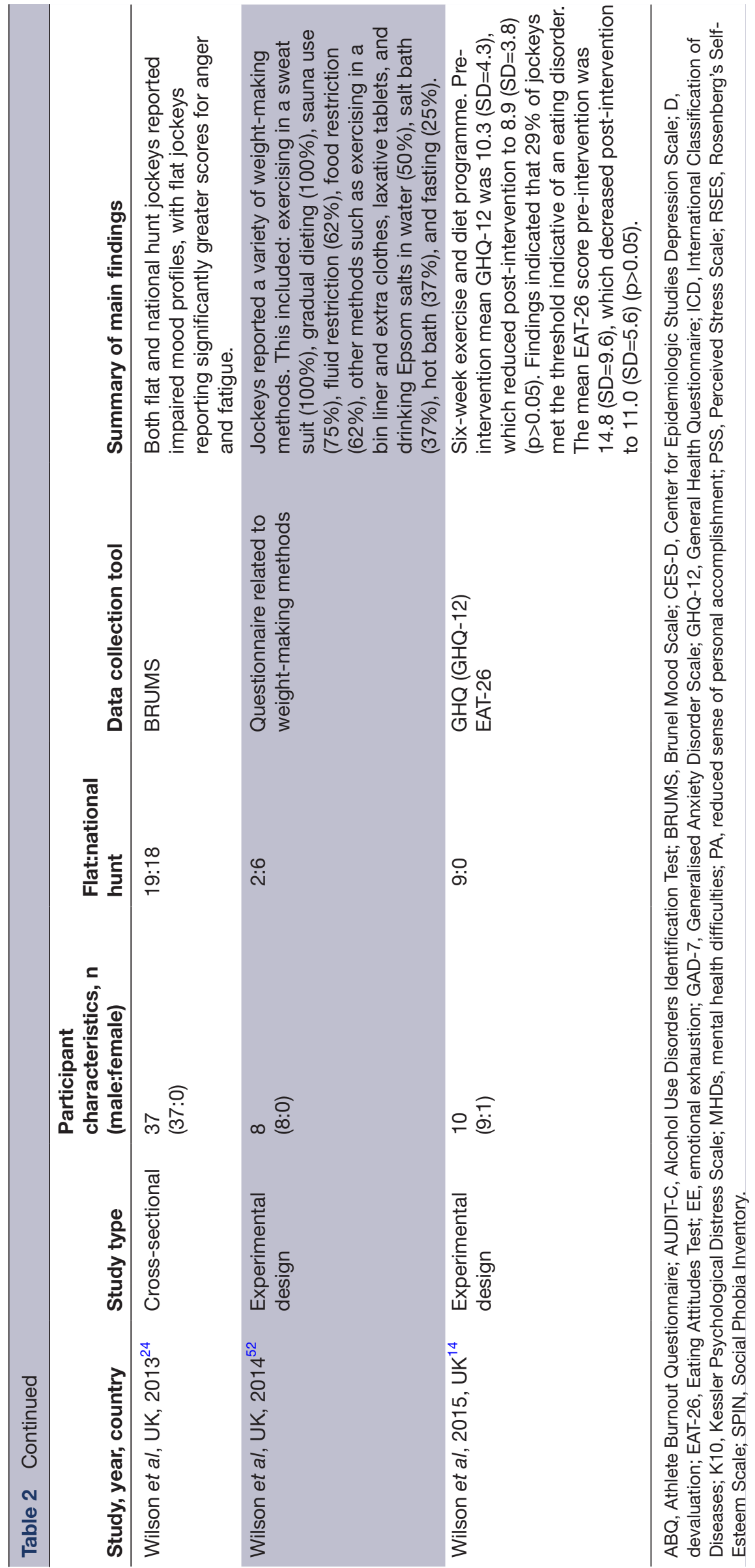


et $a l^{8}{ }^{8}$ a greater prevalence of symptoms of depression was found in national hunt jockeys $(46 \%)$ in comparison with flat jockeys (19\%). A greater risk and prevalence of injury among national hunt jockeys may begin to explain this finding, given the links between injury and MHDs with other athlete samples, ${ }^{20-22}$ although further research is needed. In comparison with flat jockeys, national hunt jockeys report a greater number of falls per 1000 rides (49.5 vs 3.8) and a higher frequency of injuries per 1000 rides (10.1 vs 1.4$).{ }^{23}$ In contrast, previous research has reported poorer mood profiles for flat jockeys, possibly due to their need to reach lower competitive riding weights. ${ }^{24}$ Differences in depression prevalence between the two studies ${ }^{68}$ may be partially explained by the sample sizes. Losty $e t a l^{8}$ gathered data from 42 professional jockeys (27\% response rate), while King et at obtained data from 84 professional jockeys (52\% response rate). Jockeys appear to report depressive symptoms more commonly than athletes in other sports. Within two recent Australasian studies of elite athletes (multiple team and individual sport athletes) using the CES-D, $27.2 \%$ of Australian athletes met depression caseness, ${ }^{25}$ while $21 \%$ of a New Zealand sample (multiple team and individual sport athletes) reported symptoms consistent with depression. ${ }^{26} \mathrm{~A}$ recent comparative meta-analysis of high performance athlete data reported rates of depressive symptoms ranging $3.7 \%-26.7 \%$ and $9.8 \%-36.5 \%$ for male and female athletes, respectively. ${ }^{27}$ The gender ratio observed is largely in keeping with the general adult population, where women have long been noted to be diagnosed with depression twice as commonly as men. ${ }^{28}$ In this context, the findings of Losty $e t a l^{8}$ and King $e t$ $a t^{6}$ are even more striking, given that the vast majority of their sample populations were men $(76 \%$ and $93 \%$, respectively), and therefore expected to be less likely to report depressive symptoms than their female counterparts (the predominantly male samples are representative of the wider jockey population internationally although a greater number of female jockeys are entering the sport each year). Further studies exploring depression would benefit from the use of diagnostic clinical interviews, although these may ultimately prove impractical and jockeys may be reluctant to participate, fearing a loss of anonymity. In the absence of interviews, the use of screening tools such as the Patient Health Questionnaire ${ }^{29}$ may more accurately predict the prevalence of depression, given that it better reflects the International Classification of Diseases-10 diagnostic criteria for the disorder, which requires a minimum symptom duration of 2 weeks.

Specific risk factors for depression have also been documented among the jockey population. Given the sport's high-risk nature, Losty $e t a l^{8}$ examined associations between injury status (eg, currently injured vs not injured) and prevalence of depressive symptoms. The study found that injured jockeys were 46 times more likely to meet the threshold for depression. This aligns with other research with elite athletes which has identified injury as a potential risk factor for depression. ${ }^{30-32}$ Moreover, social anxiety or high levels of perceived stress increased the likelihood of reporting depressive symptoms by 6.82 and 14.44 times, respectively. These associations indicate the importance of mental health support strategies with a specific focus on stress management and coping with injury. The study of King $e t a t^{6}$ also examined risk factors for depression including athlete burnout, social support, career satisfaction and contemplating retirement. No statistically significant associations were observed. Further research is required to clearly identify specific risk factors for depression among jockeys. The exploration of sport-specific risk factors, such as those related to weight and weightmaking strategies, or trauma symptoms after witnessing a fatal injury to a horse, ${ }^{7}$ is required. Previous research has suggested that the loss or injury of a horse can have profound psychological effects on riders, with responses such as devastation, feeling cheated, restlessness and isolation all significantly impacted by the severity of a horse's injury among young equestrian riders. ${ }^{33}$ Among jockeys however, data are limited.

Multiple studies have examined the mood of jockeys, often in the context of making weight. The sport of horse racing places jockeys under relentless pressure to maintain low competition weights throughout the competitive season, with qualitative research highlighting that weightrelated factors are all consuming for jockeys. ${ }^{72} 16$ Unlike other weight classification sports such as boxing or wrestling, jockeys are required to weigh a specific weight before each race, which can be challenging given a jockey may compete multiple times per day. This is due to a process called handicapping, with weight restrictions placed on horses, which the jockey must align their weight with, to increase the competitiveness of a race. Given these demands, jockeys often engage in rapid weight loss strategies, with the use of a sauna and food/ fluid restriction the most common weight loss methods used by jockeys. ${ }^{4}$ Most studies in this area have typically examined weight and mood via utilisation of the Brunel Mood Scale (BRUMS), ${ }^{34}$ a self-report 24-item abridged version of the Profile of Mood States. ${ }^{35}$ The BRUMS' measures include five negative mood states (depression, anger, tension, fatigue and confusion) and one positive mood state (vigour), and research suggests that making low riding weights is associated with more negative mood profiles. A 2008 study of 41 professional jockeys found that participants' mood profiles were significantly different at minimum weights (achieved via rapid weight loss) than at optimal (not excessively restricting weight; feeling healthy) and relaxed (no rides at light weights in the near future or no rides at all).$^{10}$ That is, when making minimum weights, jockeys reported significantly greater scores for depression, anger and fatigue, while vigour was observed to be reduced. No significant differences were found between optimal and relaxed weights. Wilson $e t a l^{24}$ reported on the mood profiles of UK flat and national hunt jockeys. Abnormal mood profiles for all measures were reported on the BRUMS except for tension. Flat 
jockeys reported significantly poorer scores for anger and fatigue variables in comparison with national hunt jockeys, perhaps due to the need to reach lower competitive riding weights.

Given these findings, several studies have highlighted the effects of making weight without the need for dehydration and food restriction with promising results. A case study which included a jockey engaging in a structured exercise and diet plan found that the individual reported a switch from above anger and depression BRUMS score pre-intervention to below average scores post-intervention, with vigour scores moving in the opposite direction. ${ }^{13}$ Positive findings were also reported in larger scale intervention via a 6 -week individually tailored diet plan in UK jockeys $(n=10)$. Jockeys' mean General Health Questionnaire scores, ${ }^{36}$ a measure of psychological distress, reduced from $10.3(\mathrm{SD}=4.3)$ pre-intervention, to $8.9(\mathrm{SD}=3.8)$ post-intervention. ${ }^{14}$ The number of jockeys who met the threshold indicative of psychiatric caseness also dropped from two to one post-intervention. The findings suggest that further educational programmes or support from practitioners on effective weight-making practices are required for jockeys. Moreover, as highlighted by Martin et al, ${ }^{16}$ further research may also seek to explore the apparent reluctance to adopt a healthier approach to riding by jockeys, as currently a reliance on older, less effective methods appears dominant.

\section{Anxiety}

Several of the studies examining jockeys' mental health also attempted to assess anxiety. A study by Losty $e t a l^{8}$ investigating 42 Irish jockeys found that $21.4 \%$ of jockeys (flat-14.3\%; national hunt-28.6\%) met caseness for generalised anxiety based on self-report measures via the Generalised Anxiety Disorder-7 questionnaire. Comparable rates were demonstrated in the study of King $e t a l,{ }^{6}$ who found that $27 \%$ of professional jockeys (flat-27\%; national hunt-28\%) met the threshold using the same questionnaire. Individual studies examining the prevalence of generalised anxiety among Swedish elite athletes (multiple individual and team sport athletes) $(12.6 \%),{ }^{37}$ rugby league players $(14.6 \%)^{38}$ and elite soccer players $(1.4 \%)^{39}$ suggest that prevalence of generalised anxiety symptoms are greater among professional jockeys than other athletes. Given that generalised anxiety is often comorbid with symptoms of other anxiety disorders such as panic disorder, social anxiety disorder and posttraumatic stress disorder, ${ }^{40}$ screening measures designed to assess generalised anxiety symptoms among jockeys may aid early identification of other potential MHDs.

Specific risk factors for generalised anxiety symptoms among jockeys include athlete burnout, career dissatisfaction and contemplating retirement. ${ }^{6}$ Athlete burnout is characterised by three components: emotional exhaustion (EE), sport devaluation (D) and a reduced sense of personal accomplishment (PA). ${ }^{41} \mathrm{~A}$ one-unit increase on the athlete burnout questionnaire increased the odds of professional jockeys meeting the threshold for generalised anxiety by 4.7 (EE), 3 (D) and 2.9 (PA) times, respectively. ${ }^{6}$ A recent qualitative study identified several factors that may contribute to burnout symptomology in professional jockeys such as intense working hours, career uncertainty and lengthy competitive seasons. ${ }^{7}$ The study by King $e t a t^{6}$ also explored career satisfaction and the contemplation of retirement as risk factors for MHDs within jockeys. Lower levels of career satisfaction increased the odds of meeting the threshold for generalised anxiety by 1.11 for each one-unit decrease on the career satisfaction scale. ${ }^{42}$ Moreover, $29 \%$ of jockeys were classified as dissatisfied with their careers. This research corroborates other studies which have highlighted career satisfaction, or lack of, as a risk factor for MHDs. ${ }^{43}$ Exploration of the factors which contribute to the career dissatisfaction of a jockeys is necessary which may begin to shed further insight to other risk factors for MHDs. This may include elevated levels of stress, vast workloads, lack of job security or financial uncertainty. ${ }^{72}$ Finally, $26 \%$ of jockeys reported the contemplation of retirement from the sport within the next 12 months, indicative of the uncertainty associated with the career cited elsewhere. ${ }^{79}$ Contemplating retirement increased the odds of meeting the criteria for generalised anxiety by 4.16 . Research examining retirement within athletes has often described the transitional process from athlete to retired athlete as one that may have implications to their mental health, however the findings presented, alongside other research in New Zealand, ${ }^{26}$ suggest that supporting athletes prior to retirement is equally as important.

\section{Distress}

Three studies explored distress among professional jockeys. ${ }^{6814}$ Losty $e t a l^{8}$ reported a prevalence of symptoms of distress among $36 \%$ of jockeys, with a mean score for the group $(\mathrm{M}=21.12, \mathrm{SD}=7.33)$ approaching the clinical cut-off of 22, based on the Kessler Psychological Distress Scale. ${ }^{44}$ No significant differences were observed between flat and national hunt jockeys. In the study of King $e t a l,{ }^{6}$ using the same measure, $19 \%$ of professional jockeys met the caseness for distress, while the mean score for symptoms of distress reported by professional jockeys was significantly lower than previously reported $(\mathrm{M}=16.7, \mathrm{SD}=6.0)$. Flat jockeys reported greater symptoms of distress in comparison with national hunt jockeys $(\mathrm{M}=17.8, \mathrm{SD}=6.5$ vs $\mathrm{M}=15.9, \mathrm{SD}=5.4)$, although no significant difference was identified. Prevalence of distress was significantly associated with athlete burnout (EE$\mathrm{OR}=5.3,95 \%$ CI 2.3 to $12.4 ; \mathrm{D}-\mathrm{OR}=7.9,95 \%$ CI 2.9 to 21.7; $\mathrm{PA}-\mathrm{OR}=8.0,95 \% \mathrm{CI} 2.8$ to 23.1 ), career satisfaction $(\mathrm{OR}=0.8,95 \% \mathrm{CI} 0.7$ to 0.9$)$ and the contemplation of retirement (OR=0.13, 95\% CI 0.04 to 0.4). Among Australian elite athletes, prevalence of distress has been reported between $17 \%$ and $35 \%,{ }^{25} 45$ suggesting that prevalence of distress among professional jockeys may be similar to other elite athletes. Another study examined distress symptoms among professional jockeys using the General Health Questionnaire, ${ }^{36}$ and found that 
$21 \%$ of jockeys could be classified as 'likely' to be experiencing distress symptoms that require support from a professional. Accurate comparisons of distress are often challenging due to the multiple measures used with elite athlete samples, with many studies using the shorter form Distress Screener, ${ }^{46}$ comprising only three questions. Moving forward, employing the use of a sport-specific distress scale with elite athletes may be advantageous in allowing comparisons between groups of athletes and also increasing detection of subclinical distress symptoms. The recently developed Athlete Psychological Strain Questionnaire (APSQ) ${ }^{47}$ represents a potential solution to such issues. The questionnaire consists of three factors related to self-regulation (eg, I found it difficult to do what I needed to do), performance (eg, I could not stop worrying about injury or my performance) and external coping (eg, I needed alcohol or other substances to relax). As highlighted in a recent review examining the mental health of cricketers, ${ }^{48}$ the APSQ could be integrated into screening measures adopted by medical teams. For professional jockeys, the APSQ may be delivered on renewing their jockey licence every 2 years, while also integrated into common practice throughout the competitive season, at potentially high-risk periods (eg, intense parts of the season), during injury rehabilitation programmes and post-concussion assessments. As such, multiple data points would improve precision of when and where professional jockeys require support, and what specific types of support are more useful (eg, developing coping strategies during injury rehabilitation).

\section{Disordered eating}

Jockeys may be more susceptible to disordered eating behaviours and attitudes than other weight-making athletes as a result of them being required to ride at low weights throughout their careers. ${ }^{10}$ This struggle to make weight has been compounded by gradual anthropometric changes among the general population (increased mean height and body mass) not being mirrored by equivalent adjustments to riding weights. ${ }^{49}$ Cullen et a $t^{49}$ observed that the average trainee jockey's weight entering the Racing Academy and Centre of Education had increased by $47 \%$ in the preceding 30 years compared with only a $10 \%$ increase of the minimum riding weight. Disordered eating practices employed by jockeys to make weight include food and/or fluid restriction, abstinence (ie, starvation), overexercising, the use of saunas or sweat suits, drinking fluids to feel full and smoking cigarettes. ${ }^{15} 1850-52$ Studies have also identified forced vomiting (known as 'flipping' within the racing industry) as an additional strategy. ${ }^{151651}$ Martin et $a l^{16}$ concluded that self-induced vomiting is typically performed as a function to attempt to promote weight loss, rather than evidence of a desire for thinness or a disturbance of body image, as seen in some eating disorders. The use of laxatives, appetite suppressants and diuretics has also been described, although all three have been prohibited among jockeys worldwide since 1999. ${ }^{11151618195152}$
Much of the research examining jockeys' psychological relationships with food has used the Eating Attitudes Test (EAT-26), a 26-item self-report questionnaire that screens for possible eating disorders. ${ }^{53}$ Mezey and King ${ }^{51}$ were the first to use the tool to report mean scores of jockeys $(M=14.9)$, with none of the participants meeting the diagnostic criteria for an eating disorder during an additional clinical interview. In the study of Caulfield and Karageorghis, ${ }^{10}$ findings demonstrated the negative influence of weight-making on attitudes towards eating. That is, jockeys scored poorer on the EAT-26 when making their minimum weight than at optimal weight or relaxed weight. A total of six jockeys (from a sample of 41) scored 20 or more on the scale, the threshold deemed indicative of the potential presence of an eating disorder. The findings suggest that jockeys' attitudes towards eating may become more disordered while trying to reach minimum riding weights. Moreover, within a 6 -week diet and exercise intervention programme, $28.6 \%$ of jockeys at baseline exceeded the EAT-26 threshold for a potential eating disorder diagnosis. ${ }^{14}$ Reassessment post-intervention found a non-significant improvement in eating attitudes (14.8-11.0). Jockeys' attitudes towards eating appear to be influenced by four key themes according to Martin et al. ${ }^{16}$ First, a reluctance to change, particularly among older jockeys, due to routine practices developed throughout their careers. Second, a lack of identification as an athlete, with disparities reported between the life and career of a jockey and other elite athletes. Third, denial and bargaining of current eating practices (eg, current practices are not too bad for the jockey). Lastly, the horse is the athlete, with the jockey placing greater emphasis on the horse's performance than their own athletic performance. The findings indicate that not only are nutritional educational programmes necessary for jockeys, but a shift in the culture towards a career as a jockey itself.

\section{Substance misuse}

Jockeys are subject to alcohol and drug testing, focused primarily on performance-impairing substances (eg, cocaine, cannabis), in order to provide a safe environment for competition. Riding under the influence of alcohol or drugs not only poses a serious risk to the individual jockey, but also to other jockeys in the race and their horses. Few studies have attempted to ascertain levels of substance misuse although King et at reported that $61 \%$ of jockeys met the clinical threshold for adverse alcohol use based on the Alcohol Use Disorders Identification Test ${ }^{54}$ questionnaire. These figures are concerning given a recent meta-analysis examining the prevalence of MHD among elite athletes found that $19 \%$ of athletes met the threshold for alcohol misuse. ${ }^{32}$ Incidence for substance misuse does however appear to vary considerably between sports. Jockey alcohol misuse is significantly greater than that reported among soccer players ${ }^{55}$ and Dutch elite athletes ${ }^{31}$ but comparable with recent figures published for rugby league players. ${ }^{56}$ In the UK, $13.33 \%$ 
and $5.33 \%$ of jockeys reported problems due to alcohol and illegal drug use, respectively. ${ }^{12}$ The disparity between reported prevalence rates of alcohol misuse identified in Ireland and the UK suggests that further research is required in this field. It may be the case that jockeys typically under-report alcohol and substance misuse for fear of losing career opportunities or risking suspension from competition.

\section{Help-seeking}

Despite an estimated 38\% of the European population experiencing an MHD each year, ${ }^{57}$ most people do not seek help from professional psychological services, or the process of accessing services is often substantially delayed. ${ }^{58}$ Consequences may include worsened symptoms over time, interpersonal problems and lower life expectancy. ${ }^{59}$ For athletes, help-seeking is also low, ${ }^{60}$ with similar findings reported among professional jockeys. King $e t a t^{6}$ found that while almost $80 \%$ of jockeys met the threshold for at least one MHD, only $33 \%$ of the sample had sought professional help. Moreover, the rates of help-seeking observed are likely inflated due to many jockeys reporting a sport psychologist as professional psychological support, where seeking help may have been solely related to performance issues, rather than for MHDs. Empirical research pertaining to helpseeking among jockeys is limited, although a survey in the UK highlighted several factors that may promote a reluctance to seek help. ${ }^{12}$ The most prominent barriers included a need to appear strong in front of others and a stigma towards accessing support services. These findings corroborate other research with athletic samples that identified stigma as a key barrier to accessing professional support. ${ }^{60-62}$ Other barriers in the study included a lack of time, ambivalence towards treatment, confidentiality concerns and difficulty finding local support. Anti-stigma campaigns, focusing on reducing both public and self-stigma, may be effective among jockeys. Moreover, programmes that focus on mental health literacy may also be considered due to the need to educate jockeys about specific symptoms of MHDs, reduce stigma and increase awareness of sources of help.

\section{Recommendations and future directions in brief}

Given the findings reported through the review, a number of recommendations and future directions are proposed. First, longitudinal studies that examine lifestyle and sport-specific stressors are required to determine the prominent factors in the development of MHDs among jockeys. Particular attention to weight-making and weight management may be fruitful given the magnitude of its importance throughout a jockey's career. Yet, the longterm impacts of such aspects on MHDs are unknown. Recent research has suggested that depressive and anxiety symptoms are greater among retired jockeys in comparison with other populations ${ }^{63}$ and the relentless necessity to compete at low weights throughout a career may be a factor. Also, despite a number of contemporary studies exploring the prevalence of symptoms of MHDs within the jockey population, samples are predominantly male. As such, further research exploring female jockeys may shed light on gender differences between male and female jockeys. Studies exploring lesser reported clinical MHDs within jockey academic literature (eg, schizophrenia) are also recommended.

Programmes designed to support jockeys for MHDs are needed, although organisations should be considerate of the horse racing environment, particularly important as jockeys perceive stigma as a key barrier to help-seeking. ${ }^{12}$ The development of a mental health and well-being framework ${ }^{64}$ within horse racing organisations may begin to standardise the care of jockeys who are experiencing an MHD, but also to promote early intervention and prevention strategies. Naturally, each iteration of the framework may look and serve differently dependent on the organisation. This is an important consideration given the cultural differences in attitudes towards MHDs ${ }^{65}$ and the popularity of horse racing worldwide. Four key components are reported by Purcell et al, ${ }^{64}$ discussed in table 3 , with specific recommendations made for the jockey population.

\section{Strengths and limitations}

The strengths of this paper are:

1. It is the first review article to explore professional jockeys' mental health beyond the negative impact of weight-making.

2. The review is designed to help inform practitioners and researchers working with jockeys on the prevalence of symptoms associated with MHDs which may improve professional practice. Organisations may also consider the recommendations proposed throughout the review article to maximise jockeys' welfare.

3. Literature searches and the application of the inclusion and exclusion criteria were conducted independently by two authors in order to minimise selection bias.

The limitations of the present paper are:

1. Although a search protocol was implemented, the best practice approach of a preregistered review was not adopted in the present review. As such, studies may not have been identified for inclusion due to the nonsystematic search process employed. The benefits of preregistration include the development of study aims and objectives to answer a specific research question, but also to avoid bias and increase transparency by detailing data analysis intentions in advance. ${ }^{66}$ Moreover, the validity and quality of studies included in the review were not assessed.

2. While the search strategy was broad, encompassing a wide variety of MHDs, it is possible that less common MHDs may not have been identified.

\section{CONCLUSION}

The review suggests that jockeys report a prevalence of symptoms associated with MHDs. It appears that jockeys 
Table 3 Jockeys' mental health and well-being framework, adapted from Purcell et a/ ${ }^{64}$

\begin{tabular}{ll}
\hline Stage & Recommendation \\
\hline Preventative & Mental health screening on licensing courses for jockeys, and at regular periods throughout the \\
& season that may increase the risk of MHDs such as injury or a loss of competitive rides. \\
& Athlete development. Developing awareness for jockeys outside of the sport of horse racing is \\
& important given jockeys' unidimensional identity. ${ }^{11}$ This could involve programmes related to dual \\
& career and planning for life after a career as a jockey. \\
& Development of bespoke, mental health literacy programmes. Given jockeys' workload and time \\
& constraints, programmes may be delivered online and shorter in length (eg, 1 hour).
\end{tabular}

At risk - prevention Increase visibility of services that may increase the likelihood of a referral to mental health professionals. This may occur from members of a multidisciplinary team (eg, strength and conditioning coach, nutritionist, sport psychologist, physios, medical officers). Organisations can also play a role by promoting services at racetracks and through jockey support networks (eg, jockey associations).

$\begin{array}{ll}\text { Early intervention } & \begin{array}{l}\text { Within-organisation supports are preferred, such as sport or clinical psychologists, or medical officers. } \\ \text { If other professionals are required, in-house supports should refer to external services. Careful } \\ \text { consideration should be made to the type of professional contacted given the unique, nuanced nature } \\ \text { of a career as a jockey. Given the current climate in the COVID-19 pandemic, online or telephone } \\ \text { support services may be most appropriate. }\end{array} \\ \begin{array}{l}\text { Specialist mental } \\ \text { healthcare }\end{array} & \begin{array}{l}\text { A standardised mental health emergency plan should be in place, with agreement between support } \\ \text { staff as to what does and does not constitute as a mental health emergency. Moreover, it is paramount } \\ \text { that procedures are in place for the jockey if a mental health emergency occurs. A return to riding plan } \\ \text { should also be created to promote a safe and healthy return to the sport. }\end{array}\end{array}$

MHDs, mental health difficulties.

experience depressive and anxiety symptoms with much greater frequency than other athletes, despite male jockeys continuing to account for the majority of the professional ranks. Depressive symptoms are strongly associated with injury and stress, suggesting that support initiatives should focus on assisting jockeys to cope better with each of these factors. Distress symptoms reported by jockeys appear largely comparable with other athletes. Risk factors for anxiety and distress symptoms include athlete burnout, career dissatisfaction and the contemplation of retirement. Substance misuse, particularly adverse alcohol use, appears substantially greater for jockeys than that observed in many studies examining team and individual athletes. Further longitudinal epidemiological studies are necessary, ideally with data gathered from jockeys in differing racing jurisdictions. Much of the data throughout the review are taken from European jockeys, therefore jockeys from other popular racing areas (eg, Australia, USA, Hong Kong) are under-represented.

Disordered eating behaviours are common, but with no clear findings from the eating attitudes data, they appear largely to be long-established methods of attempting to make weight, rather than indicative of a high prevalence of clinical eating disorders. Such behaviours (eg, wasting) are accepted and embedded within the culture of horse racing performance. ${ }^{11} 16$ Lastly, help-seeking among the jockey population appears low, with research highlighting that stigma and the need to appear stoic reported as key barriers to accessing professional psychological support services. Jockey-specific programmes that consider the profession's unique stressors and sports culture are required. These programmes should be designed to increase mental health literacy, reduce stigma and provide jockeys with access to confidential services.

Twitter Lewis King @LewisKing17

Acknowledgements The authors would like to thank the Irish Horseracing Regulatory Board for funding the ongoing research project exploring jockeys' mental health.

Contributors LK and GW screened articles for the manuscript. LK wrote the manuscript with support from GW, SJC and CL. SJC, CL and GW helped supervise the project. AM and JP provided further feedback on the manuscript.

Funding The Irish Horseracing Regulatory Board funded the project as part of a current $\mathrm{PhD}$ programme.

Competing interests None declared.

Patient consent for publication Not required.

Provenance and peer review Not commissioned; externally peer reviewed.

Open access This is an open access article distributed in accordance with the Creative Commons Attribution Non Commercial (CC BY-NC 4.0) license, which permits others to distribute, remix, adapt, build upon this work non-commercially, and license their derivative works on different terms, provided the original work is properly cited, appropriate credit is given, any changes made indicated, and the use is non-commercial. See: http://creativecommons.org/licenses/by-nc/4.0/.

\section{ORCID iD}

Lewis King http://orcid.org/0000-0002-7864-9606

\section{REFERENCES}

1 Cullen S, Dolan E, McGoldrick A, et al. The impact of makingweight on cognitive performance in apprentice jockeys. J Sports Sci 2015;33:1589-95.

2 Warrington G, Dolan E, McGoldrick A, et al. Chronic weight control impacts on physiological function and bone health in elite jockeys. J Sports Sci 2009;27:543-50.

3 O'Connor S, Warrington G, McGoldrick A, et al. Race day concussion incidence in Irish professional flat and jump horse racing from 2011 to 2016. J Sci Med Sport 2017;20:20-1. 
4 Wilson G, Drust B, Morton JP, et al. Weight-making strategies in professional jockeys: implications for physical and mental health and well-being. Sports Med 2014;44:785-96.

5 Wilson G, Hill J, Martin D, et al. GB apprentice jockeys do not have the body composition to make current minimum race weights: is it time to change the weights or change the jockeys? Int J Sport Nutr Exerc Metab 2020:101-4.

6 King L, Cullen SJ, O'Connor S. Common mental disorders among Irish jockeys: prevalence and risk factors. Phys Sportsmed 2020;49:1-7.

7 King L, Cullen S, Mcgoldrick A, et al. Stressors experienced by professional jockeys (in press). Sport Psychol.

8 Losty C, Warrington G, McGoldrick A, et al. Mental health and wellbeing of jockeys. J Hum Sport Exerc 2019;14:147-58.

9 Landolt K, O'Halloran P, Hale MW, et al. Identifying the sources of stress and rewards in a group of Australian apprentice jockeys. Qual Res Sport Exerc Health 2017;9:583-99.

10 Caulfield MJ, Karageorghis Cl. Psychological effects of rapid weight loss and attitudes towards eating among professional jockeys. $J$ Sports Sci 2008;26:877-83.

11 McGuane T, Shannon S, Sharp L-A, et al. "You Wanna Ride, Then You Waste": The Psychological Impact of Wasting in National Hunt Jockeys. Sport Psychol 2019;33:129-36.

12 McConn-Palfreyman W, Littlewood M, Nesti M. A lifestyle rather than a job' A review and recommendations on mental health support within the British horse racing industry. Racing Found, 2019: 1-90. https://www.racingfoundation.co.uk/storage/app/media/downloads/ A-lifestyle-rather-than-a-job.pdf

13 Wilson G, Chester N, Eubank M, et al. An alternative dietary strategy to make weight while improving mood, decreasing body fat, and not dehydrating: a case study of a professional jockey. Int J Sport Nutr Exerc Metab 2012;22:225-31.

14 Wilson G, Pritchard PP, Papageorgiou C, et al. Fasted exercise and increased dietary protein reduces body fat and improves strength in jockeys. Int J Sports Med 2015;36:1008-14.

15 Dolan E, O'Connor H, McGoldrick A, et al. Nutritional, lifestyle, and weight control practices of professional jockeys. J Sports Sci 2011;29:791-9.

16 Martin D, Wilson G, Morton JP, et al. The horseracing industry's perception of nutritional and weight-making practices of professional jockeys. Qual Res Sport Exerc Health 2017;9:568-82.

17 Leydon MA, Wall C. New Zealand jockeys' dietary habits and their potential impact on health. Int $J$ Sport Nutr Exerc Metab 2002;12:220-37.

18 Labadarios D, Kotze J, Momberg D, et al. Jockeys and their practices in South Africa. World Rev Nutr Diet 1993;71:97-114.

19 Moore JM, Timperio AF, Crawford DA, et al. Weight management and weight loss strategies of professional jockeys. Int $J$ Sport Nutr Exerc Metab 2002;12:1-13.

20 Cox CE, Ross-Stewart L, Foltz BD. Investigating the prevalence and risk factors of depression symptoms among NCAA division I collegiate athletes. J Sport Sci 2017;5.

21 Gouttebarge V, Tol JL, Kerkhoffs G. Epidemiology of symptoms of common mental disorders among elite Gaelic athletes: a prospective cohort study. Phys Sportsmed 2016;44:283-9.

22 Rice SM, Gwyther K, Santesteban-Echarri O, et al. Determinants of anxiety in elite athletes: a systematic review and meta-analysis. $\mathrm{Br} \mathrm{J}$ Sports Med 2019;53:722-30.

23 O'Connor S, Warrington G, McGoldrick A, et al. Epidemiology of injury due to Race-Day Jockey falls in professional flat and jump horse racing in Ireland, 2011-2015. J Athl Train 2017;52:1140-6.

24 Wilson G, Fraser WD, Sharma A, et al. Markers of bone health, renal function, liver function, anthropometry and perception of mood: a comparison between flat and national Hunt Jockeys. Int J Sports Med 2013;34:453-9.

25 Gulliver A, Griffiths KM, Mackinnon A, et al. The mental health of Australian elite athletes. J Sci Med Sport 2015;18:255-61.

26 Beable S, Fulcher M, Lee AC, et al. SHARPSports mental health awareness research project: prevalence and risk factors of depressive symptoms and life stress in elite athletes. J Sci Med Sport 2017;20:1047-52.

27 Gorczynski PF, Coyle M, Gibson K. Depressive symptoms in high-performance athletes and non-athletes: a comparative metaanalysis. Br J Sports Med 2017;51:1348-54.

28 Alonso J, Angermeyer MC, Bernert S, et al. Prevalence of mental disorders in Europe: results from the European study of the epidemiology of mental disorders (ESEMeD) project. Acta Psychiatr Scand Suppl 2004:21-7.

29 Kroenke K, Spitzer RL. The PHQ-9: a new depression diagnostic and severity measure. Psychiatr Ann 2002;32:509-15.
30 Kilic Özgür, Aoki H, Haagensen R, et al. Symptoms of common mental disorders and related stressors in Danish professional football and handball. Eur J Sport Sci 2017;17:1328-34.

31 Gouttebarge V, Jonkers R, Moen M, et al. The prevalence and risk indicators of symptoms of common mental disorders among current and former Dutch elite athletes. J Sports Sci 2017:35:2148-56.

32 Gouttebarge V, Castaldelli-Maia JM, Gorczynski P, et al. Occurrence of mental health symptoms and disorders in current and former elite athletes: a systematic review and meta-analysis. Br J Sports Med 2019;53:700-6.

33 Davies $\mathrm{E}$, James $\mathrm{S}$. The psychological responses of amateur riders to their horses' injuries. Comp Exerc Physiol 2018;14:135-42.

34 Terry PC, Lane AM, Lane HJ, et al. Development and validation of a mood measure for adolescents. J Sports Sci 1999;17:861-72.

35 McNair D, Lorr M, Droppleman L. Manual for the profile of mood states. San Diego, CA: Educational and Industrial Testing Services, 1971.

36 Goldberg DP, Gater R, Sartorius N, et al. The validity of two versions of the GHQ in the WHO study of mental illness in general health care. Psychol Med 1997;27:191-7.

37 Åkesdotter C, Kenttä G, Eloranta S, et al. The prevalence of mental health problems in elite athletes. J Sci Med Sport 2020;23:329-35.

38 Du Preez EJ, Graham KS, Gan TY, et al. Depression, anxiety, and alcohol use in elite rugby League players over a competitive season. Clin J Sport Med 2017;27:530-5.

39 Junge A, Feddermann-Demont N. Prevalence of depression and anxiety in top-level male and female football players. BMJ Open Sport Exerc Med 2016;2:e000087.

40 Löwe B, Decker O, Müller S, et al. Validation and standardization of the generalized anxiety disorder screener (GAD-7) in the general population. Med Care 2008:46:266-74.

41 Raedeke TD, Smith AL. Development and preliminary validation of an athlete burnout measure. J Sport Exerc Psychol 2001;23:281-306.

42 Greenhaus JH, Parasuraman S, Wormley WM. Effects of race on organizational experiences, job performance evaluations, and career outcomes. Acad Manag J 1990;33:64-86.

43 Foskett RL, Longstaff $\mathrm{F}$. The mental health of elite athletes in the United Kingdom. J Sci Med Sport 2018;21:765-70.

44 Kessler RC, Barker PR, Colpe LJ, et al. Screening for serious mental illness in the general population. Arch Gen Psychiatry 2003;60:184-9

45 Purcell R, Rice S, Butterworth M, et al. Rates and correlates of mental health symptoms in currently competing elite athletes from the Australian National high-performance sports system. Sports Med 2020;50:1683-94.

46 Braam C, van Oostrom SH, Terluin B, et al. Validation study of a distress screener. J Occup Rehabil 2009;19:231-7.

47 Rice SM, Parker AG, Mawren D, et al. Preliminary psychometric validation of a brief screening tool for athlete mental health among male elite athletes: the athlete psychological strain questionnaire. Int $J$ Sport Exerc Psychol 2020;18:850-65.

48 McCabe T, Peirce N, Gorczynski P, et al. Narrative review of mental illness in cricket with recommendations for mental health support. BMJ Open Sport Exerc Med 2021;7:e000910.

49 Cullen S, Donohoe A, McGoldrick A, et al. Musculoskeletal health, kidney and liver function in retired jockeys. Int J Sports Med 2015;36:968-73.

50 Cotugna N, Snider OS, Windish J. Nutrition assessment of horseracing athletes. J Community Health 2011;36:261-4.

51 Mezey G, King M, Mezey G. Brief communication eating behaviour of male racing jockeys. Psychol Med 1987;17:249-53.

52 Wilson G, Hawken MB, Poole I, et al. Rapid weight-loss impairs simulated riding performance and strength in jockeys: implications for making-weight. J Sports Sci 2014;32:383-91.

53 Garner DM, Olmsted MP, Bohr Y, et al. The eating attitudes test: psychometric features and clinical correlates. Psychol Med 1982;12:871-8.

54 Dawson DA, Grant BF, Stinson FS, et al. Effectiveness of the derived alcohol use disorders identification test (AUDIT-C) in screening for alcohol use disorders and risk drinking in the US general population. Alcohol Clin Exp Res 2005;29:844-54.

55 Gouttebarge V, Aoki H, Kerkhoffs G. Symptoms of common mental disorders and adverse health behaviours in male professional soccer players. J Hum Kinet 2015;49:277-86.

56 Du Preez E, Graham K, Gan T, et al. Mental health issues in elite rugby League players in the NRL during a competitive season - a cross sectional epidemiological study. J Sci Med Sport 2017:20:72-4. 
57 Wittchen $\mathrm{H}-\mathrm{U}$, Jacobi F. Size and burden of mental disorders in Europe--a critical review and appraisal of 27 studies. Eur Neuropsychopharmacol 2005;15:357-76.

58 Wang PS, Angermeyer M, Borges G, et al. Delay and failure in treatment seeking after first onset of mental disorders in the world Health organization's world mental health survey initiative. World Psychiatry 2007;6:177-85.

59 Schnyder N, Panczak R, Groth N, et al. Association between mental health-related stigma and active help-seeking: systematic review and meta-analysis. Br J Psychiatry 2017;210:261-8.

60 Castaldelli-Maia JM, Gallinaro JGdeME, Falcão RS, et al. Mental health symptoms and disorders in elite athletes: a systematic review on cultural influencers and barriers to athletes seeking treatment. $\mathrm{Br}$ J Sports Med 2019;53:707-21.

61 López RL, Levy JJ. Student athletes' perceived barriers to and preferences for seeking counseling. J Coll Couns 2013;16:19-31.

62 Gulliver A, Griffiths KM, Christensen H. Barriers and facilitators to mental health help-seeking for young elite athletes: a qualitative study. BMC Psychiatry 2012;12:157.
63 Mackinnon A-L, Jackson K, Kuznik K, et al. Increased risk of musculoskeletal disorders and mental health problems in retired professional Jockeys: a cross-sectional study. Int J Sports Med 2019;40:732-8

64 Purcell R, Gwyther K, Rice SM. Mental health in elite athletes: increased awareness requires an early intervention framework to respond to athlete needs. Sports Med Open 2019;5:1-8.

65 Kotera Y, Van Laethem M, Ohshima R. Cross-cultural comparison of mental health between Japanese and Dutch workers: relationships with mental health shame, self-compassion, work engagement and motivation. Cross Cult Strateg Manag 2020;27:511-30.

66 Quintana DS. From pre-registration to publication: a non-technical primer for conducting a meta-analysis to synthesize correlational data. Front Psychol 2015;6:1549.

67 WHO. Promoting Mental Health : concepts, emerging evidence, practice (Summary Report), 2004. Available: https://www.who.int/ mental_health/evidence/en/promoting_mhh.pdf [Accessed 6 Apr 2020].

68 Common mental health problems: identification and pathways to care clinical guideline. London 2011. 